\title{
Interplay between LXR and Wnt/ $\beta$-Catenin Signaling in the Negative Regulation of Peripheral Myelin Genes by Oxysterols
}

\author{
Joelle Makoukji, ${ }^{1}$ Ghjuvan'Ghjacumu Shackleford, ${ }^{1}$ Delphine Meffre, ${ }^{1}$ Julien Grenier, ${ }^{1}$ Philippe Liere, ${ }^{2}$ \\ Jean-Marc A. Lobaccaro, ${ }^{3}$ Michael Schumacher, ${ }^{2}$ and Charbel Massaad ${ }^{1}$ \\ ${ }^{1}$ University Paris Descartes, Unité Mixte de Recherche (UMR) 8194, Centre National de la Recherche Scientifique (CNRS), 75270 Paris, France, ${ }^{2}$ UMR 788 , \\ Inserm and University Paris-Sud 11, Institut Fédératif de Recherche 93, 94276 Le Kremlin-Bicêtre, France, and ${ }^{3}$ UMR CNRS and University Blaise Pascal \\ 6547, and Centre de Recherche en Nutrition Humaine d'Auvergne, 63177 Aubière, France
}

\begin{abstract}
Oxysterols are reactive molecules generated from the oxidation of cholesterol. Their implication in cholesterol homeostasis and in the progression of neurodegenerative disorders is well known, but few data are available for their functions in the peripheral nervous system. Our aim was to study the influence of oxysterols on myelin gene expression and myelin sheath formation in peripheral nerves. We show by gas chromatography/mass spectrometry that Schwann cells and sciatic nerves contain 24(S)-hydroxycholesterol, 25hydroxycholesterol, and 27-hydroxycholesterol and that they express their biosynthetic enzymes and receptors (liver X receptors LXR $\alpha$ and LXR $\beta$ ). We demonstrate that oxysterols inhibit peripheral myelin gene expression [myelin protein zero (MPZ) and peripheral myelin protein-22 (PMP22)] in a Schwann cell line. This downregulation is mediated by either $\operatorname{LXR} \alpha$ or $\operatorname{LXR} \beta$, depending on the promoter context, as suggested by siRNA strategy and chromatin immunoprecipitation assays in Schwann cells and in the sciatic nerve of LXR knock-out mice. Importantly, the knock-out of LXR in mice results in thinner myelin sheaths surrounding the axons. Oxysterols repress myelin genes via two mechanisms: by binding of LXRs to myelin gene promoters and by inhibiting the Wnt/ $\beta$-catenin pathway that is crucial for the expression of myelin genes. The Wnt signaling components (Disheveled, TCF/LEF, $\beta$-catenin) are strongly repressed by oxysterols. Furthermore, the recruitment of $\beta$-catenin at the levels of the MPZ and PMP22 promoters is decreased. Our data reveal new endogenous mechanisms for the negative regulation of myelin gene expression, highlight the importance of oxysterols and LXR in peripheral nerve myelination, and open new perspectives of treating demyelinating diseases with LXR agonists.
\end{abstract}

\section{Introduction}

The myelination of axons is a complex process performed by Schwann cells in the peripheral nervous system (PNS) (Garbay et al., 2000). Peripheral myelin genes Myelin Protein Zero (MPZ) and Peripheral Myelin Protein-22 (PMP22) expression is tightly regulated in Schwann cells (Niemann et al., 2006). A slight change in PMP22 or MPZ expression has a deep impact on the development and preservation of nerve fibers and their myelin sheaths, as observed in Charcot-Marie-Tooth disease (Roa et al., 1996).

Few cellular signals are known to directly regulate the myelin genes expression. We have shown that steroid hormones (Désarnaud et al., 2000) and more recently that the canonical Wnt/ $\beta$-catenin signaling pathway is a direct driver of myelin gene

Received Feb. 8, 2011; revised May 5, 2011; accepted May 11, 2011.

Author contributions: P.L. and C.M. designed research; J.M., G.'G.S., D.M., J.G., and J.-M.A.L. performed research; J.-M.A.L. contributed unpublished reagents/analytic tools; P.L. and C.M. analyzed data; M.S. and C.M. wrote the paper.

This work was funded by Inserm, CNRS, University Paris Descartes, University Paris Sud 11, and the Association Française contre les Myopathies. J.M. and G.'G.S. received PhD fellowships from the French Ministry of Research. We acknowledge Dr. Alain Schmitt of the Cochin Imaging Facility.

Correspondence should be addressed to Prof. Charbel Massaad, CNRS, UMR 8194, Université Paris Descartes, 45 rue des Saints-Pères, 75270, Paris Cedex 6, France. E-mail: charbel.massaad@parisdescartes.fr.

DOI:10.1523/JNEUROSCI.0761-11.2011

Copyright $\odot 2011$ the authors $\quad 0270-6474 / 11 / 319620-10 \$ 15.00 / 0$ expression. Inactivation of Wnt components in zebrafish embryos or in mouse Schwann cells led to severe dysmyelination and the inhibition of myelin gene expression (Tawk et al., 2011). However, endogenous factors involved in the inhibition of myelin gene expression have so far been neglected.

Oxysterols are natural compounds originating from the enzymatic oxidation of cholesterol. There are different oxysterols, in particular 24(S)-hydroxycholesterol [24(S)-OH], 25hydroxycholesterol (25-OH), and 27-hydroxycholesterol (27-OH), which are, respectively, synthesized by means of the cholesterol hydroxylase CYP46A1, CH25H, and CYP27A1 $\alpha$ (Russell, 2000). They are implicated in cholesterol turnover, inflammation, and neurodegenerative diseases such as Alzheimer's disease (Lütjohann et al., 2000; Papassotiropoulos et al., 2002) and multiple sclerosis (Leoni et al., 2002; Teunissen et al., 2003). Glial cells are also targets for the oxysterol action: they inhibit astrocyte proliferation after brain injury (Bochelen et al., 1995) and cause oligodendrocyte apoptosis (Trousson et al., 2009).

Oxysterols are natural ligands for liver X receptors (LXRs) (Janowski et al., 1996), which has two isoforms: $\operatorname{LXR} \alpha$ and LXR $\beta$. LXRs regulate gene expression by binding to responsive elements (LXRE). In the absence of ligands, LXRs bind to corepressors (Chen and Evans, 1995; Hörlein et al., 1995). In response to 

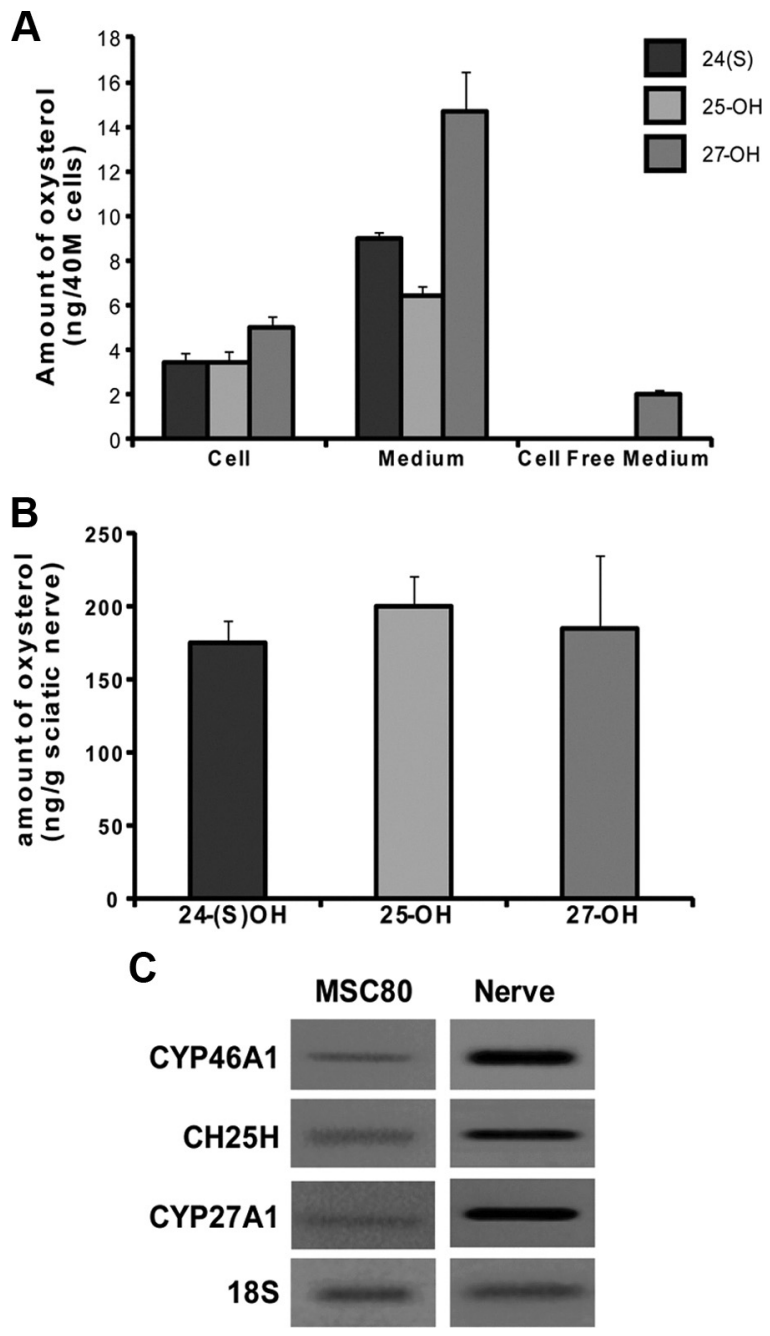

Figure 1. Analysis of oxysterols by GC/MS and expression of their biosynthetic enzymes in MSC80 cells and mouse sciatic nerve. $A, M S C 80$ cells were cultured under normal conditions. After $72 \mathrm{~h}$, medium and cells were separated to measure oxysterols by GC/MS. Results are expressed in nanograms per 40 million $(M)$ cells and represent the means \pm SEM of three independent experiments performed in duplicate. $\boldsymbol{B}, 0$ xysterols were extracted from sciatic nerves of 8-week-old mice and were analyzed by GC/MS. Results are expressed in nanograms per gram of sciatic nerve tissue and represent the means \pm SEM of eight independent experiments performed in duplicate. C, Total RNA from MSC 80 cells and mouse sciatic nerves was prepared. qRT-PCR experiments were performed by using primers recognizing specifically CYP46A1, CH25H, or CYP27A1. PCR products were analyzed on agarose gel (2\%) and visualized under UV. 18S RNA was detected by specific primers and used to normalize the expression levels.

oxysterols binding, they interact with coactivators (Huuskonen et al., 2004) to transactivate. In the case of inflammatory genes, LXR is able to repress transcription in the presence of ligands by recruiting coregulator (Wang et al., 2008).

Studies with transgenic mice revealed important roles of LXRs within the nervous system (Andersson et al., 2005). $L X R \beta^{-1-}$ or $L X R \alpha / \beta^{-/-}$transgenic mice show several defects, such as axonal atrophy, neuronal loss, astrogliosis, and lipid accumulation in specific brain regions. Nevertheless, the role of oxysterols and LXRs has remained unexplored in the PNS, in particular their potential influence in myelination.

Here, we report a major role of oxysterols in the PNS. We showed that oxysterols are produced by a Schwann cell line and in sciatic nerves and that they inhibit peripheral myelin gene expression by mechanisms involving LXR and the Wnt/ $\beta$-catenin path-
A
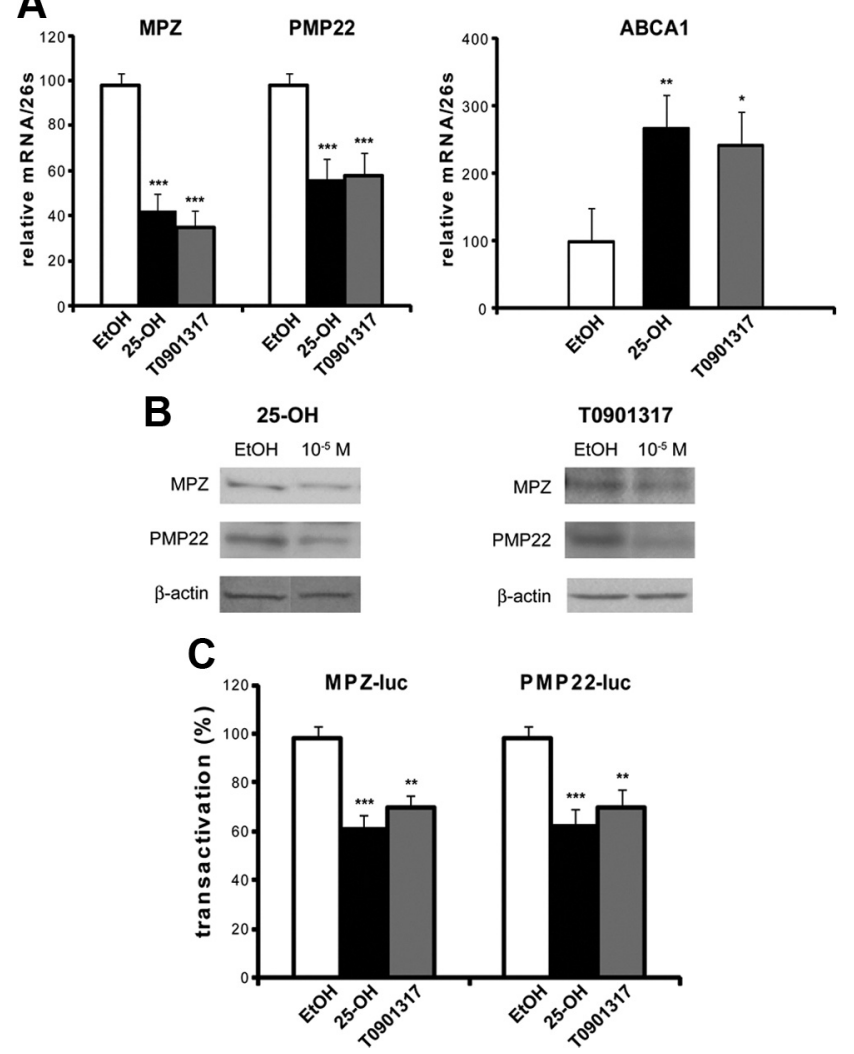

Figure 2. Effects of oxysterols on the expression of MPZ and PMP22 in MSC 80 cells. A, MSC80 cells were treated with ethanol (vehicle), $25-0 \mathrm{H}$, or T0901317 at $10 \mu \mathrm{m}$ during $24 \mathrm{~h}$. Total RNA was extracted, and quantitative real-time PCR experiments were performed using primers recognizing MPZ, PMP22, or ABCA1. The RT-PCR was normalized using 265 RNA, and they represent the mean \pm SEM of at least four independent experiments. $\boldsymbol{B}$, MSC 80 cells were treated with ethanol (vehicle), 25-0H, or T0901317 at $10 \mu \mathrm{m}$ during $24 \mathrm{~h}$. Western blots were performed using either anti-MPZ or anti-PMP22 antibodies to verify their expression in MSC80 cells. $\beta$-Actin was used to normalize the Western blots. Results were reproduced in three independent experiments, and figures represent a typical experiment. C, MSC80 cells were transiently transfected with MPZ-Luc or PMP22-Luc constructs. Sixteen hours after transfection, cells were incubated with 25 - $0 \mathrm{H}$ or $\mathrm{T} 0901317$ at $10 \mu \mathrm{m}$ for $24 \mathrm{~h}$, and then $\beta$-galactosidase and luciferase activities were analyzed. Results represent the means \pm SEM of at least 11 independent experiments performed in duplicate. ${ }^{*} p<0.05,{ }^{* *} p<0.01,{ }^{* * *} p<0.001$ by Tukey's post hoc tests after one-way ANOVA when compared with control.

way. Furthermore, $L X R \alpha / \beta^{-/-}$knock-out (KO) mice exhibit thinner myelin sheaths around their axons. Our results show, for the first time, the implication of LXR and oxysterols in the negative regulation of myelin gene expression.

\section{Materials and Methods}

Animals. Eight-week-old male mice (C57BL/6:129Sv) were purchased from Janvier. $L X R \alpha / \beta^{-/-}$knock-out mice and their wild-type (WT) controls were maintained on a mixed strain background (C57BL/6: 129Sv) and housed in a temperature-controlled room with a $12 \mathrm{~h}$ light/ dark cycle (Cummins and Mangelsdorf, 2006). All experiments were performed on age-matched male mice ( 8 weeks old). Animals were fed ad libitum with water and Global-diet 2016S from Harlan containing 16\% protein, $4 \%$ fat, and $60 \%$ carbohydrates. To reduce the effect of stress, the elapsed time between the capture of a mouse and its death by decapitation was under $30 \mathrm{~s}$. Sciatic nerves were collected and frozen in liquid nitrogen. All aspects of animal care were approved by the Regional Ethic Committee (authorization CE2-04).

Cell culture. The mouse Schwann cell line (MSC80) was maintained in DMEM supplemented with $10 \%$ decomplemented fetal calf serum (Hyclone-Perbio), $1 \%$ penicillin, $1 \%$ streptomycin (Invitrogen), and 1\% 
glutamine. All cultures were grown at $37^{\circ} \mathrm{C}$ in a humidified atmosphere of $5 \% \mathrm{CO}_{2}$.

Plasmids and chemicals. MPZ promoter-luciferase reporter (MPZ-Luc) was graciously provided by Dr. G. Lemke (The Salk Institute, La Jolla, CA) and PMP22-Luc by Dr. P. Patel (Baylor College of Medicine, Houston, TX). The siRNAs directed against $\operatorname{LXR} \alpha$ and $\operatorname{LXR} \beta$ were purchased from Dharmacon. Each LXR isoform was targeted by four different separate siRNA recognizing four different regions of LXR transcripts. The siRNA that we have used did not have any off-target effect. $25-\mathrm{OH}$ was purchased from Sigma-Aldrich and TO901317 from SPI-Bio.

Transient transfections. MSC80 cells were transiently transfected using Effecten reagent (Qiagen). One day before the transfection, MSC80 cells $\left(1.5 \times 10^{5}\right.$ cells per well $)$ were grown into six-well plate and incubated in the DMEM culture medium containing $10 \%$ decomplemented fetal calf serum. The MPZ-Luc or the PMP22-Luc plasmid $(0.3 \mu \mathrm{g})$, the pRSV- $\beta$-galactosidase expression vector $(0.1$ $\mu \mathrm{g}$ ), and siRNAs at the concentrations indicated in the figure legends were mixed with a solution containing Effecten reagents (0.85 $\mathrm{mg} / \mathrm{ml}$ ) in DMEM. The mixture was then added to the cells and incubated overnight. Sixteen hours after transfection, the medium was replaced by DMEM with or without $25-\mathrm{OH}(10 \mu \mathrm{M})$ or TO901317 $(10 \mu \mathrm{M})$. Luciferase activity was determined using the enzymatic method described by Massaad et al. (2000). The $\beta$-galactosidase activity was used to normalize the transfection efficiency.

Quantitative and semiquantitative RT-PCR experiments. Total RNA from cultured MSC80 was obtained using RNA NOW (Ozyme). One microgram was reverse transcribed with random primers from Promega and reverse transcriptase MMLV-RT from Invitrogen. PCR experiments were performed using TaqDNA polymerase purchased from Promega and primers specific to each gene from Operon. PCR products were analyzed on agarose gel (2\%) and visualized under UV.

Quantitative real-time PCR was performed with standard protocols using SYBRGreen ROX Mix (ABgene) as a fluorescent detection dye in ABI PRISM 7000 in a final volume of $10 \mu \mathrm{l}$, which also contains $300 \mathrm{nM}$ primers (Operon) and $20 \mathrm{ng}$ of reverse-transcribed RNA in 384-well plates. To characterize the generated amplicons and to control the contamination by unspecific byproducts, a melting curve analysis was applied. Each reaction was performed in triplicate, and the mean of at least three independent experiments was calculated. All results were normalized to the $26 \mathrm{~S}$ mRNA level and calculated using the $\Delta \mathrm{Ct}$ method. The primer sequences used in real-time PCR included the following: MPZ forward (F), 5'GTCAAGTCCCCCAGTAGAA3'; MPZ reverse (R), 5'AGGAGCAAGAGGAAAGCAC3'; PMP22 F, 5'AATGGACACACGACTGATC3'; PMP22 R, 5'CCTTTGGTGAGAGTGAAGAG3'; LXR $\alpha$ F, 5'CAATGCCTGATGTTTCTCC3'; LXR $\alpha$ R, 5'TGACTCCAACCCTATCCCTA3'; LXR $\beta$ F, 5'CTTGGTGGTGTCTTCTTGA3'; LXR $\beta$ R, 5'TGTGGTAGGCTGAGGTGTA3'; CYP46A1 F, 5'ATGCCAGGGAAGAGAAAGC3'; CYP46A1 R, 5'CTTTGAGGATCTGCGTGAG3'; CH25H F, 5'ACCCACTCACCATCTTTAC3'; CH25H R, 5'GCCCAGCATTTTGTCCCA3'; CYP27A1 F, 5'AGACCATCGGCACCTTTC3'; CYP27A1 R, 5'GCACCACACCAGTCACTT3'; Disheveled 2 (DVL2) F, 5'GGCTTGTGTCGTCAGATACC3'; DVL2 R, 5'TTTCATGGCTGCTGGATAC3'; DVL3 F, 5'CCGATGAGGATGATTCCACC3'; DVL3 R,
A

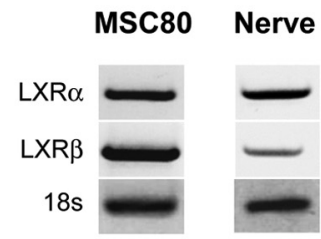

MPZ

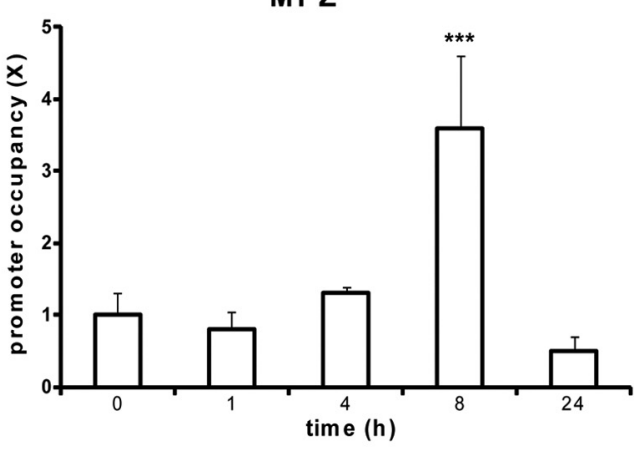

PMP22

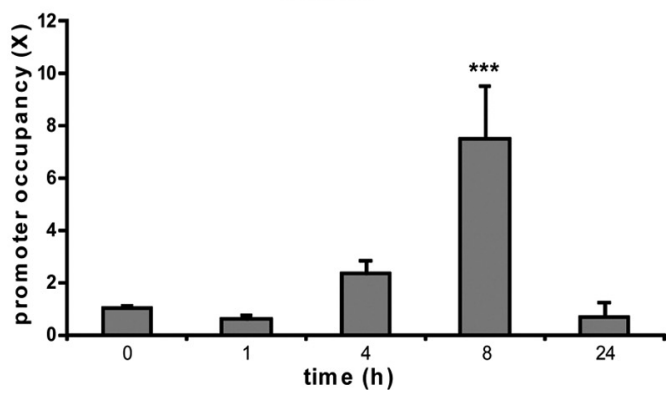

time (h)

Figure 3. Expression of $L X R \alpha$ and $L X R \beta$ and their implication in MPZ promoter activity in MSC 80 cells. $A$, Total RNA from MSC 80 cells or mouse sciatic nerves was prepared. RT-PCR experiments were performed by using primers recognizing specifically LXR $\alpha$ or . Products were analyzed on agarose gel (2\%) and visualized under UV. 18S RNA was detected by specific primers and MatInspector software (Genomatix). To examine the occupancy of these sites by LXRs, cells were treated or not with $25-\mathrm{OH}(10 \mu \mathrm{m})$ ments. Results are the mean of at least four independent experiments. ${ }^{* *} p<0.001$ by Tukey's post hoc tests after one-way ANOVA when compared with control.

5'TGAGGCACTGCTCTGTTCTG3'; TCF1 F，5'TCAAGAGGTGGGGGATTAGA3'; TCF1 R, 5'GCAGGAGAAGCATTTGTAGG3'; LEF1 F, 5'AAGCCTCAACACGAACACAG3'; LEF1 R, 5'TGCACTCAGCTACGACATTC3'; TCF3 F, 5'ACCCCTTCCTGATGATTCC3'; TCF3 R, 5'CGACCTTGTGTCCTTGACT3'; $\beta$-catenin F, 5'GCCACAGGATTACAA GAAGC3'; $\beta$-catenin R, 5'CCACCAGAGTGAAAAGAACG3'; $18 \mathrm{~S}$ F, 5'CTACCACATCCAAGGAAGGC3'; 18S R, 5'CTCGGGCCTGCTTTGAACAC3; 26S F, 5'AGGAGAAACAACGGTCGTGCCAAAA3'; 26S R, 5'GCGCAAGCAGGTCTGAATCGTG3'; LXRE F, 5'GGTCCTGAGTTCAAATCCC3'; LXRE R, 5'GAACCTTCATCTGTTGTTGG3'; LXRE/pregnane X receptor response element (PXRE) F, 5'GCTTTCAGGTTCAGGGACA3'; LXRE/PXRE R, 5'TGGGA GATACACAAGCTGGA3'; ABCA1 F, 5' CTGTTTCCCCCAA CTTCTG $3^{\prime}$; and ABCA1 R, 5' TCTGCTCCATCTCTGCTTTC $3^{\prime}$.

Antibodies. Primary antibodies against MPZ (rabbit polyclonal) and PMP22 (rabbit polyclonal) were purchased from Abcam and $\beta$-catenin and LXR (mouse monoclonal) from BD Biosciences. Secondary antibodies used for Western blotting were HRP-conjugated goat anti-mouse IgG and HRP-conjugated goat anti-rabbit IgG (Millipore).

Western blot. Protein content was determined using the "RC DC" protein assay kit (Bio-Rad) with BSA as standard. Aliquots of $20 \mu \mathrm{g}$ of total MSC80 extracts treated or not with $25-\mathrm{OH}$ or TO901317 $(10 \mu \mathrm{M})$ 
were used for each sample. Homogenate proteins were separated on 15\% SDS-PAGE and blotted onto polyvinylidene difluoride (PVDF) membranes. Nonspecific binding sites in the transblots were blocked at $4^{\circ} \mathrm{C}$ overnight with $2 \%$ ECL Advance blocking agent (GE Healthcare) with $0.1 \%$ Tween 20 (Invitrogen) in PBS. Membranes were then incubated at room temperature for $2 \mathrm{~h}$ with the following primary antibodies diluted in a mixture of $2 \%$ ECL Advance blocking agent and PBS-0.1\% Tween: MPZ antibody (1:750), PMP22 antibody (1:750), $\beta$-catenin antibody $(1: 1000)$, and $\beta$-actin antibody $(1: 10,000)$. They were then incubated at room temperature for $1 \mathrm{~h} 30 \mathrm{~min}$ with the appropriate secondary antibody diluted in $2 \%$ blocking buffer/PBS- $0.1 \%$ Tween (anti-rabbit at 1:20,000; anti-mouse at 1:20,000), followed by ECL Plus Western blotting detection (GE Healthcare) before exposure to radiographic film Hyperfilm ECL (GE Healthcare). Western blots were quantified by means of NIH Image J Software.

Chromatin immunoprecipitation. MSC80 cells treated with 25-OH for $1,4,8$, or $24 \mathrm{~h}$ were fixed with $1 \%$ formaldehyde added to the medium for $10 \mathrm{~min}$, scraped, and collected by centrifugation. Cells were resuspended in $300 \mu \mathrm{l} / \mathrm{ml}$ lysis buffer (5 mM PIPES, pH 8.0, $85 \mathrm{~mm} \mathrm{KCl}$, and $0.5 \%$ NP-40) with a mixture of protease inhibitors (Roche). Cells were pelleted by centrifugation and resuspended in $300 \mu \mathrm{l}$ of $1 \%$ SDS, 10 mM EDTA, and $50 \mathrm{~mm}$ Tris- $\mathrm{HCl}, \mathrm{pH} 8.0$, containing protease inhibitors. After incubation on ice for $10 \mathrm{~min}$, they were sonicated six times for $30 \mathrm{~s}$ using Bioruptor (Diagenode). Lysates were then cleared by centrifugation, and the concentration of DNA was determined. Equal amounts of DNA were diluted 10 times in dilution buffer $(0.01 \%$ SDS, $1 \%$ Triton X-100, $1.2 \mathrm{~mm}$ EDTA, 16.7 mm Tris-HCl, pH 8.1, and $167 \mathrm{~mm} \mathrm{NaCl}$ ). The chromatin solution was precleared for $1 \mathrm{~h}$ at $4^{\circ} \mathrm{C}$ on Protein A-Agarose/Salmon Sperm DNA beads from Millipore. After brief centrifugation and removal of the beads, DNA was incubated overnight at $4^{\circ} \mathrm{C}$ on a rotating wheel with $1 \mu \mathrm{g}$ of either $\beta$-catenin antibody or LXR antibody or nonrelevant antibody (anti-C23). Immune complexes were collected on Protein A-Agarose/Salmon Sperm DNA beads from Millipore. Beads were washed sequentially in TSE $(0.1 \%$ SDS, $1 \%$ Triton X-100, 2 mм EDTA, and $20 \mathrm{~mm}$ Tris-HCl, $\mathrm{pH} 8.1$ ) with $150 \mathrm{~mm} \mathrm{NaCl}$, TSE with $500 \mathrm{~mm} \mathrm{NaCl}$, buffer A $(0.25 \mathrm{~m} \mathrm{LiCl}, 1 \% \mathrm{NP}-40,1 \%$ deoxycholate, 1 mM EDTA, and 10 mм Tris-HCl, $\mathrm{pH} 8.1$ ), and two times with Tris-EDTA, and then eluted with $200 \mu \mathrm{l}$ of $1 \%$ SDS and $0.1 \mathrm{M} \mathrm{NaHCO}_{3}$. Crosslinks were reversed by heating at $65^{\circ} \mathrm{C}$ for $4 \mathrm{~h}$ after adding $\mathrm{NaCl}$ to $200 \mathrm{~mm}$ final concentration. After treatment with Proteinase $\mathrm{K}(50 \mu \mathrm{g} / \mathrm{ml})$ for $1 \mathrm{~h}$ at $37^{\circ} \mathrm{C}$, DNA was purified using Geneclean Turbo kit (Q-Biogene). Real-time PCR analysis of inputs or immunoprecipitated DNAs was performed.

Oxysterols quantification by gas chromatography/mass spectrometry. MSC80 cells $\left(40 \times 10^{6}\right.$ cells $)$ and their corresponding media were extracted separately with $10 \mathrm{vol}$ of $\mathrm{MeOH} / \mathrm{CHCl}_{3}(1: 1 \mathrm{v} / \mathrm{v})$. Thirty nanograms of ${ }^{2} \mathrm{H}_{10}-24(S)-\mathrm{OH}$ cholesterol, as internal standard, and $50 \mu \mathrm{g}$ of butylated hydroxytoluene were added into extracts for oxysterols quantification and for avoiding cholesterol autoxidation processes, respectively.

Cholesterol was separated from oxysterols by solid-phase extraction. Samples were applied in $\mathrm{CH}_{3} \mathrm{CN} /$ isopropanol $(1: 1 \mathrm{v} / \mathrm{v})$ to a $500 \mathrm{mg} \mathrm{C} 18$ cartridge (International Sorbent Technology), and oxysterols were eluted with $12 \mathrm{ml}$ of $\mathrm{CH}_{3} \mathrm{CN} /$ Isopropanol/ $\mathrm{H}_{2} \mathrm{O}$ (55:25:25 v/v/v). This fraction was further purified by means of a second solid-phase extraction with a recycling procedure (Liere et al., 2004).

The oxysterol fraction was filtered through a $0.45 \mu \mathrm{m}$ Gelman PVDF membrane and was purified by HPLC (Thermo Fisher Scientific) and collected with a fraction collector (Gilson). HPLC was achieved with a Lichrosorb Diol column as described previously (Liere et al., 2000).

The oxysterols-containing fraction from HPLC was derivatized with $\mathrm{N}$-methyl- $\mathrm{N}$-trimethylsilyltrifluoroacetamide to form the di-trimethylsilyl ether derivatives of oxysterols.

Derivatized cells and media extracts as well as derivatized calibration solutions were injected with an AS 2000 autosampler (Thermo Electron Corporation) into the gas chromatography/mass spectrometry (GC/MS) system, which consisted of a TraceGC gas chromatograph coupled with an Automass Solo mass spectrometer.
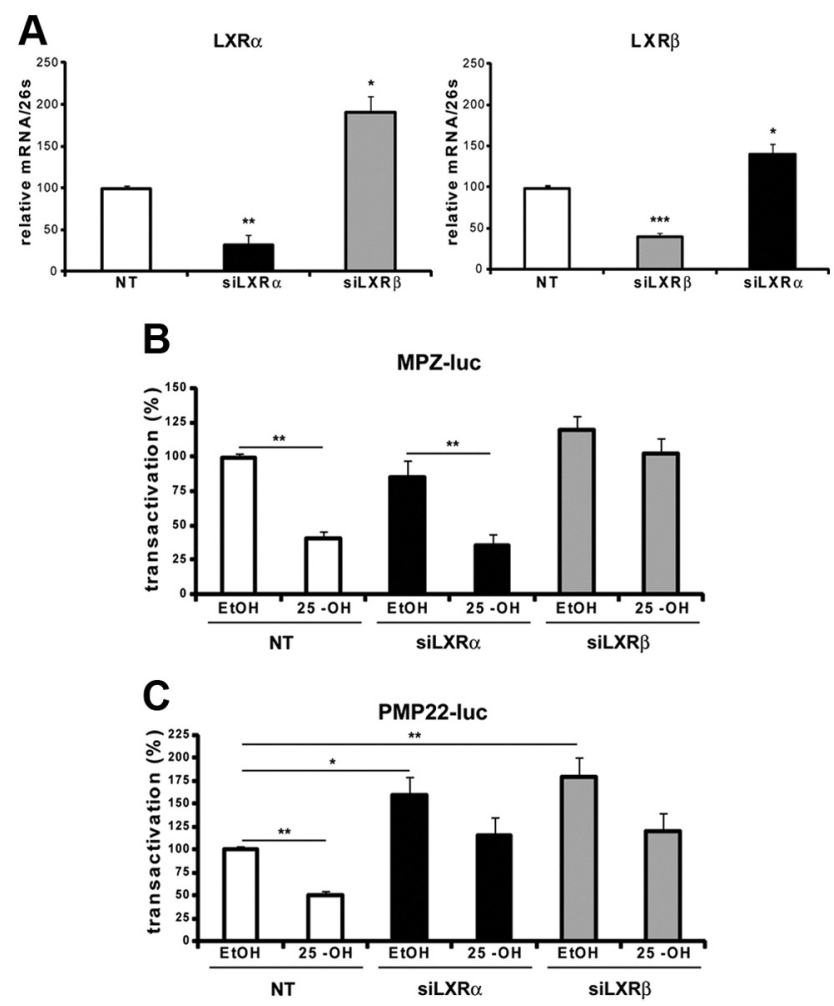

Figure 4. Implication of LXR $\alpha$ and LXR $\beta$ in MPZ and PMP22 promoter activities in MSC 80 cells. $A$, MSC80 cells were transfected with siRNA directed against LXR $\alpha$ or LXR $\beta$. The expression levels of LXR $\alpha$ and LXR $\beta$ were determined by real-time RT-PCRand normalized by using 265 RNA. MSC80 cells were transiently transfected with either MPZ-Luc (B) or PMP22-Luc ( $\boldsymbol{C}$ plasmids and with siRNA directed against $L X R \alpha$ or $L X R \beta$. Sixteen hours after transfection, cells were incubated with $25-0 \mathrm{H}$ ( 10 $\mu \mathrm{m})$ for $24 \mathrm{~h}$, and then $\beta$-galactosidase and luciferase activities were analyzed. Results represent the means \pm SEM of at least six independent experiments performed in duplicate. ${ }^{*} p<0.05$, ${ }^{* *} p<$ $0.01,{ }^{* * *} p<0.001$ by Tukey's post hoc test after one-way ANOVA when compared with control.

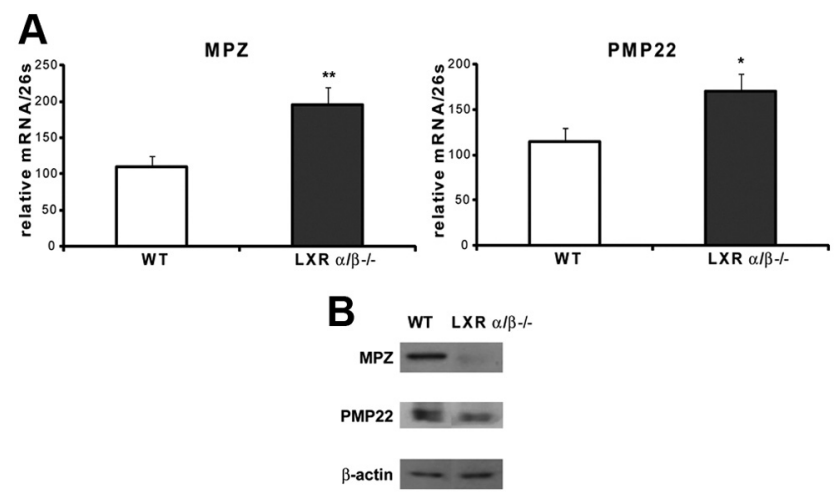

Figure 5. Expression of myelin genes in adult $L X R \alpha / \beta^{-\prime-}$ mice. Eight-week-old male $L X R \alpha / \beta^{-/-}$mice were killed, and then their sciatic nerves were dissected ( $n=6$ per group). $A$, Total RNA was extracted and quantitative real-time PCR experiments were performed using primers recognizing MPZ or PMP22. The RT-PCR was normalized using 265 RNA, and they represent the mean \pm SEM of at least six independent experiments. ${ }^{*} p<0.05$ and ${ }^{* *} p<0.01$ by Student's $t$ tests. $\boldsymbol{B}$, Proteins were extracted, and Western blots were performed using anti$M P Z$, anti-PMP22, or antibodies to verify their expression in $L X R \alpha / \beta^{-\prime-}$ mice. $\beta$-Actin was used to normalize the Western blots. These results were reproduced in three independent experiments, and figures represent a typical experiment.

GC was performed in the splitless mode with a BPX5 capillary column (SGE Analytical Science). The temperature in the oven was initially $50^{\circ} \mathrm{C}$ for $1 \mathrm{~min}$ and then ramped to $340^{\circ} \mathrm{C}$ at $20^{\circ} \mathrm{C} / \mathrm{min}$.

The mass spectrometer was operated in the electronic impact mode. Identification of each oxysterol was supported by its retention 
time and two diagnostic ions in the single ion monitoring mode. Quantification was performed according to the major diagnostic ion.

Methylene blue/azur II staining and transmission electron microscopy. Eight-week-old mice were deeply anesthetized by intraperitoneal injection of $40 \mathrm{mg} / \mathrm{kg}$ ketamine and $30 \mathrm{mg} / \mathrm{kg}$ xylazine and then intracardially perfused with $4 \%$ paraformaldehyde, $2.5 \%$ glutaraldehyde, and $0.1 \mathrm{~m}$ phosphate buffer, $\mathrm{pH}$ 7.4. Tissues were dissected and immersed in the same fixative solution at $4^{\circ} \mathrm{C}$ overnight, washed in phosphate buffer, postfixed in $2 \%$ osmium tetroxide, dehydrated in graded ethanol series, and embedded in epoxy resin. Semithin sections were cut with a glass knife at $(0.5-1 \mu \mathrm{m})$ and stained with methylene blue/azur II. For electron microscopy, ultrathin sections $(50-90 \mathrm{~nm})$ were cut on an ultramicrotome (8800 Ultrotome III; LKB Bromma) and collected on 300-mesh nickel grids. Staining was performed on drops of $4 \%$ aqueous uranyl acetate, followed by Reynolds's lead citrate (Reynolds, 1963). Ultrastructural analyses were performed in a JEOL jem-1011 electron microscope and digitalized with DigitalMicrograph software. Image acquisition was performed at the Cochin Imaging Facility. Electron microscopy images were used for calculating the g-ratio and axon perimeter using NIH ImageJ software. At least 100 randomly selected axons were analyzed per animal. At least three animals were used per genotype. Healthy axons were defined on the basis of the presence of intact membranes and the normal complement of organelles.

Statistical analysis. Unless otherwise specified, means of treatment groups were compared with one-way ANOVA. When the ANOVA showed that there were significant differences between the groups, Tukey's test was used to identify the sources of these differences. $p \leq 0.05$ was considered statistically significant. Two groups comparisons were performed by Student's $t$ test.

\section{Results}

Oxysterols are synthesized by

Schwann cells (MSC80) and

sciatic nerves

We first showed by GC/MS that MSC80 mouse Schwann cells contain oxysterols. $24(S)-\mathrm{OH}, 25-\mathrm{OH}$, and $27-\mathrm{OH}$ were detected in cell lysates and their culture media after a $48 \mathrm{~h}$ incubation (Fig. $1 A)$. Cell free media did not contain $24(S)-\mathrm{OH}$ and $25-\mathrm{OH}$ but contained a small amount of $27-\mathrm{OH}$, possibly resulting from auto-oxidation of cholesterol. Oxysterols are also present in mouse sciatic nerves (Fig. $1 B$ ) at relatively high amounts (175 ng of oxysterol per gram of tissue, which is $\sim 0.5 \mu \mathrm{M}$ ). Furthermore, we showed that the transcripts of their biosynthetic enzymes, CYP46A1 for 24( $S)-\mathrm{OH}, \mathrm{CH} 25 \mathrm{H}$ for $25-\mathrm{OH}$, and CYP27A1 for 27-OH, are expressed in MSC80 cells and in sciatic nerves of 8 -week-old mice (Fig. 1C). These results demonstrate the ability of Schwann cells to synthesize oxysterols.
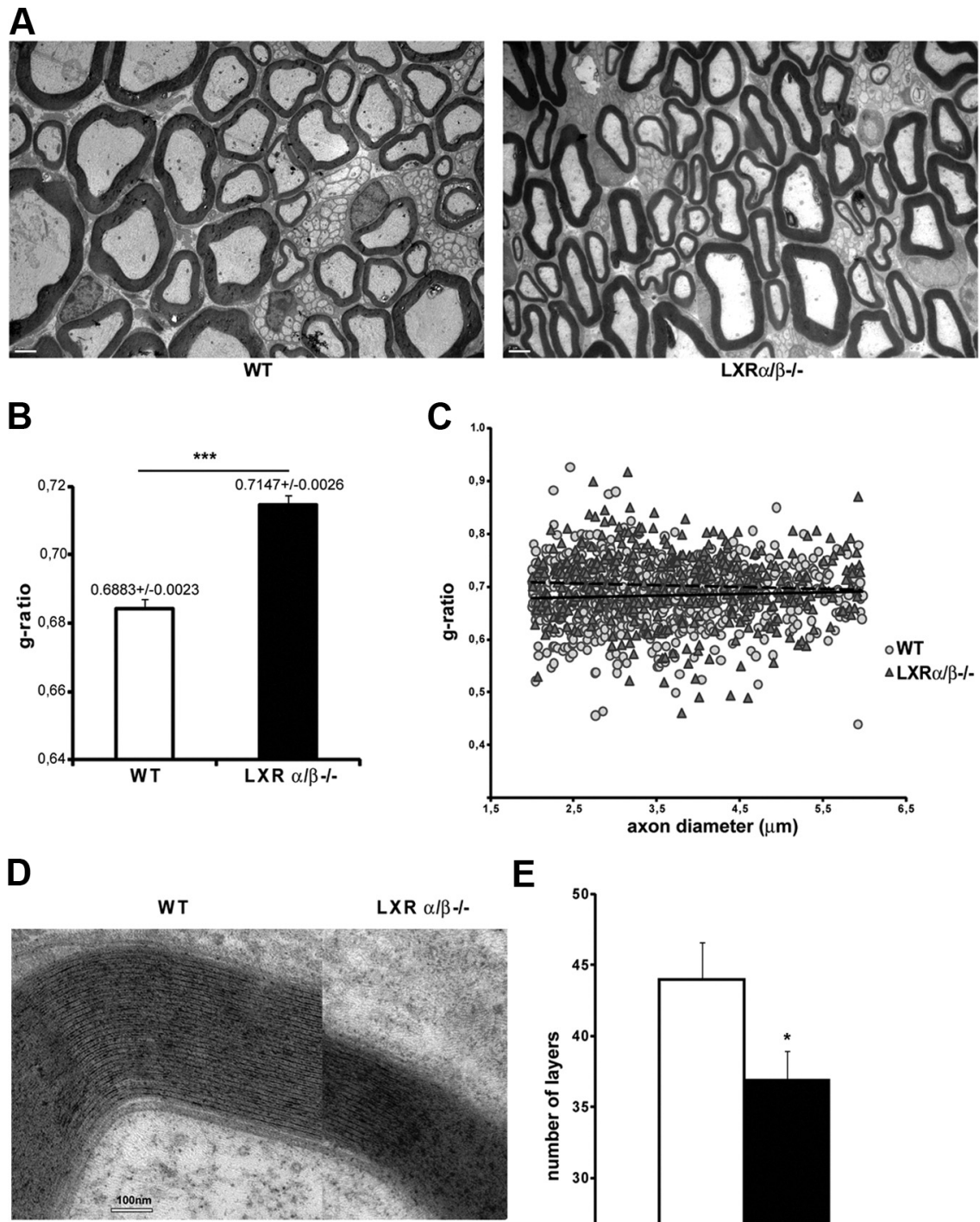

E

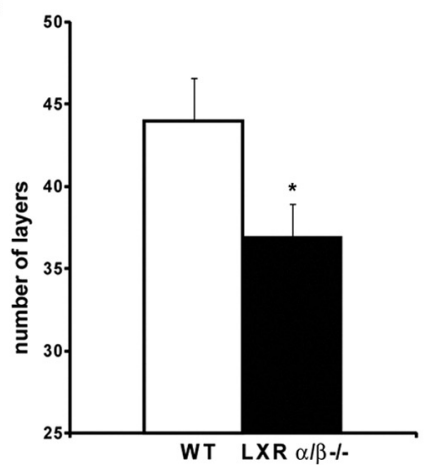

Figure 6. Incidence of LXR KO on myelin structure in vivo. $\boldsymbol{A}$, Ultrathin (50-90 nm) cross-sections were prepared from Eponembedded adult sciatic nerves and stained for myelin. Heterogeneity and reduced thickness of myelin sheaths is apparent in $L X R \alpha / \beta^{-/-}$mice when compared with WT. Scale bar, $2 \mu \mathrm{m}$. $\boldsymbol{B}$, Myelin thickness was estimated by g-ratio determination using electronic microscopy pictures obtained from adult sciatic nerves. Myelin thickness is altered in $L X R \alpha / \beta^{-/-}$mice. Three animals per genotype were used. Data are given as means \pm SEM. $C, g$-ratios were plotted against axonal diameters. The reduction in myelin thickness in $L X R \alpha / \beta^{-1-}$ mice when compared with WT was observed for nearly all types of axon calibers. Dotted line, micrographs of myelin layers from $L X R \alpha / \beta^{-1-}$ compared with WT animals. Scale bar, $100 \mathrm{~nm}$. The two axons shown are of approximately equal diameters. $\boldsymbol{E}$, Quantification of the number of layers around the axons of either WT or $L X R \alpha / \beta^{-/-}$mice. ${ }^{*} p<0.05$ and ${ }^{* * *} p<0.001$ by Student's $t$ test when compared with control (WT).

\section{Peripheral myelin genes are repressed by oxysterols in MSC80 cells}

To analyze the effects of oxysterols on the expression of myelin genes, we incubated MSC80 cells with a high physiological concentration $(10 \mu \mathrm{M})$ of either $25-\mathrm{OH}$ or the non-steroidal synthetic LXR ligand TO901317 for $24 \mathrm{~h}$. This ligand (N-(2,2,2-trifluoro-ethyl)-N-[4-(2,2,2-trifluoro-1-hydroxy-1trifluoromethyl-ethyl)-phenyl]benzenesulfonamide), was developed through structure-activity relationship studies. It shows similar efficacy to natural ligand (Schultz et al., 2000).

We showed by real-time PCR that 25-OH and TO901317 inhibited MPZ transcripts by 60 and 65\%, respectively (Fig. $2 A)$ PMP22 expression was inhibited by $40 \%$ by both drugs 
(Fig. 2A). As a control, we tested the effect of $25-\mathrm{OH}$ and TO901317 on a well-known LXR target gene, the cholesterol transporter ABCA1 (Cermenati et al., 2010). As expected, both 25-OH and TO901317 increased ABCA1 transcripts in MSC80 cells (Fig. 2A).

The inhibition of myelin mRNA was reflected at the protein level. We observed by Western blots a decrease in MPZ and PMP22 protein after incubating Schwann cells with 25-OH (64 and $69 \%$ inhibition for MPZ and PMP22, respectively) or TO901317 (67 and 59\% decrease for MPZ and PMP22, respectively) (Fig. 2 B). To assess whether 25-OH and TO901317 exert their effects at the level of the MPZ and PMP22 promoters, we performed transient transfection assays. MSC80 cells were transfected with either MPZ-Luc or PMP22-Luc constructs and then incubated with $10 \mu \mathrm{M} 25-\mathrm{OH}$ or TO901317. As shown in Figure $2 C, 25-\mathrm{OH}$ reduced by $40 \% \mathrm{MPZ}$ and PMP22 promoter activities, whereas their inhibition by TO901317 was less potent (an $\sim 30 \%$ decrease). $25-\mathrm{OH}$ also significantly inhibited myelin gene expression at a lower concentration ( $1 \mu \mathrm{M}$; data not shown).

\section{The repressing effects of oxysterols are mediated by LXR $\alpha$ or LXR $\boldsymbol{\beta}$ depending on the promoter context}

To identify molecular effectors of the inhibitory effects of oxysterols on peripheral myelin genes, we studied their nuclear LXR receptors. First, we showed by PCR that the transcripts of both receptors are expressed in both MSC80 cells and in sciatic nerve (Fig. 3A). Then, we conducted chromatin immunoprecipitation (ChIP) assays to assess the recruitment of LXRs at the level of myelin gene promoters. We found in silico a potential binding site for LXRs localized at $-8508 /-8533 \mathrm{bp}$ at the level of the MPZ promoter (Fig. $3 B$ ) and a probable LXRE/PXRE located at position $-159 /-170$ of the PMP22 promoter (Fig. 3C). For MPZ, ChIP experiments revealed that LXR recruitment is enhanced fourfold after 8 h of treatment of MSC80 cells with 25-OH. In the case of the PMP22 promoter, the binding of LXR was increased eightfold after a $8 \mathrm{~h}$ treatment with $25-\mathrm{OH}$ (Fig. $3 \mathrm{C}$ ). Similar results were obtained with the synthetic LXR ligand TO901317 (data not shown). Interestingly, at $24 \mathrm{~h}$, the recruitment of LXR at the level of myelin gene promoters had returned to control levels (Fig. $3 B, C$ ).

To analyze the relative implication of either $\operatorname{LXR} \alpha$ or $\operatorname{LXR} \beta$ in myelin gene repression, we knocked down their expression by siRNA in MSC80 cells and analyzed the impact on MPZ and PMP22 promoter activities. The efficacy of each siRNA was verified by real-time PCR. Each siRNA significantly inhibited the targeted LXR (Fig. 4A). Nevertheless, we observed a compensation in the expression between both LXRs: the knockdown of LXR $\alpha$ increased by $90 \%$ the expression of LXR $\beta$, whereas the knockdown of LXR $\beta$ increased by $40 \%$ the expression of LXR $\alpha$.

As expected, 25-OH inhibited MPZ promoter activity. The knockdown of LXR $\alpha$ did not interfere with the inhibitory effect of $25-\mathrm{OH}$. A $60 \%$ inhibition of MPZ promoter activity by $25-\mathrm{OH}$ was still obtained despite the overexpression of $\operatorname{LXR} \beta$ attributable to LXR $\alpha$ knockdown. Interestingly, the knockdown of LXR $\beta$ abrogated the inhibition of MPZ expression by 25-OH (Fig. $4 B$ ), although LXR $\alpha$ was overexpressed. This result highlights the important role of LXR $\beta$ in mediating the inhibitory actions of MPZ.

Knockdown of either LXR $\alpha$ or LXR $\beta$ significantly enhanced the basal activity of the PMP22 promoter (Fig. 4C), most likely by interfering with the inhibition of endogenous oxysterols (Figs. $1 A, 2 A)$. Furthermore, both $\operatorname{LXR} \alpha$ and $\operatorname{LXR} \beta$ silencing reversed the inhibitory effect of $25-\mathrm{OH}$. These results show that both
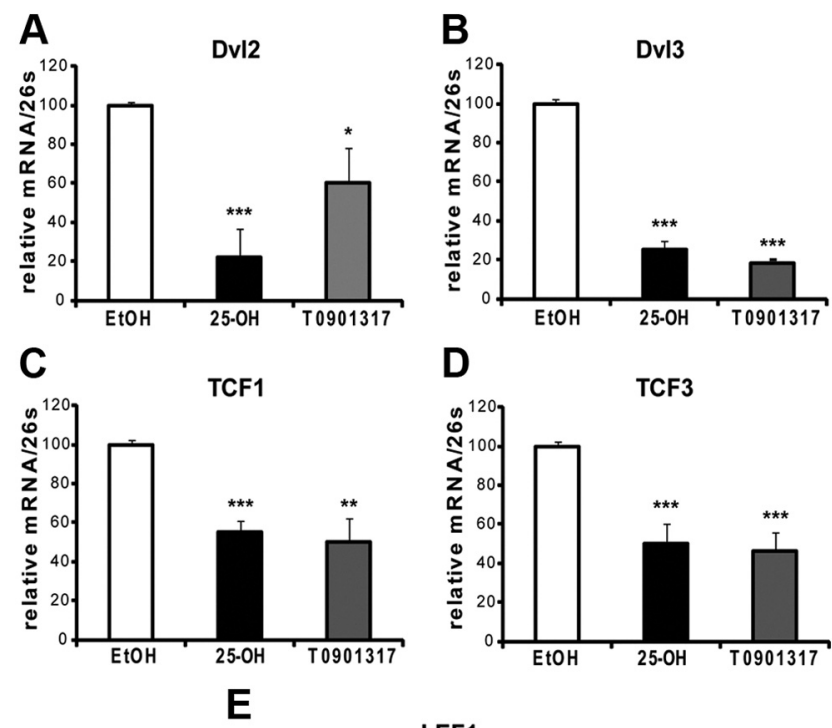

D TCF3

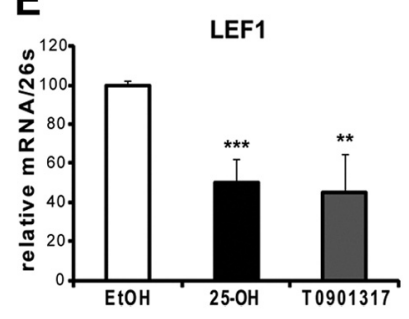

Figure 7. Effects of $25-0 \mathrm{H}$ and T0901317 on the expression of components of the Wnt signaling pathway. MSC80 cells were treated with ethanol (vehicle), 25-0H, or T0901317 at 10 $\mu \mathrm{m}$ during $24 \mathrm{~h}$. Total RNA was extracted, and quantitative real-time $P C R$ experiments were performed using primers recognizing DVL2 $(\boldsymbol{A})$, DVL3 $(\boldsymbol{B})$, TCF1 $(\boldsymbol{C})$, TCF3 $(\boldsymbol{D})$, or LEF1 (E). The qRT-PCR was normalized using 26S RNA, and they represent the means \pm SEM of at least four independent experiments. ${ }^{*} p<0.05,{ }^{* *} p<0.01$, and ${ }^{* * *} p<0.001$ by Tukey's post hoc tests after one-way ANOVA when compared with control.

LXR $\alpha$ and LXR $\beta$ mediate the inhibition of PMP2 2 promoter activity by $25-\mathrm{OH}$.

\section{LXR $\alpha$ or LXR $\beta$ knockout affects myelin structure in vivo}

Because LXR $\alpha$ and LXR $\beta$ are both expressed in sciatic nerves and affect myelin gene expression in MSC80 cells, we intended to analyze the consequences of their knock-out for the structure of myelin sheaths. First, we analyzed the expression of MPZ and PMP22 transcripts by real-time RT-PCR in sciatic nerves from adult $L X R \alpha / \beta^{-1-}$ mice (8-week-old males). The knock-out of both LXR $\alpha$ and LXR $\beta$ enhanced by twofold MPZ transcript and by $70 \%$ PMP22 mRNA expression (Fig. 5A). Unexpectedly, both MPZ and PMP22 protein expressions were decreased in $L X R \alpha /$ $\beta^{-/-}$mice (Fig. 5B). We observed a 73\% decrease for MPZ and $34 \%$ inhibition of PMP22 protein expression in $L X R \alpha / \beta^{-/-}$ mice. This finding prompted us to study the effect of the LXRs inactivation at the level of myelin structure by analyzing the diameters of sciatic nerve axons and the thickness myelin sheaths in WT and $L X R \alpha / \beta^{-1-}$ mice by electron microscopy and digital imaging of ultrathin (50-90 nm) cross-sections (Fig. 6A). In LXR double knock-out mice, the thickness of myelin sheaths was reduced, and they appeared heterogeneous when compared with controls. The g-ratios (axon diameter/diameter of nerve fibers) were calculated from no fewer than 100 myelinated axons per mouse and genotype $(n=3)$ using electron micrograph images. In WT mice, the average g-ratio was $0.6883 \pm$ 0.0023 . In contrast, the myelin of $L X R \alpha / \beta^{-/-}$was significantly thinner than that of controls (g-ratio $=0.7147 \pm 0.0026$ ), 
with some fibers having g-ratios $<0.74$, a level never observed in WT mice (Fig. 6B).

We also calculated the g-ratios of sciatic nerve fibers from LXR double KO and wild-type animals, plotted as a function of their respective axonal diameters (Fig. $6 C$ ). We concentrated our analysis on the most abundant category of axons (i.e., between 2 and $6 \mu \mathrm{m}$ ). Although the most striking differences are observed for axons with small diameter, our results also revealed a reduction in myelin thickness for nearly all axon calibers. We also calculated the number of myelin sheaths layers for the same category of axons. As depicted in Figure $6 D$, the myelin sheath is thicker in wild-type animals versus $L X R \alpha / \beta^{-/-}$ mice. Indeed, number of myelin layers around the axons is significantly lower in $L X R \alpha / \beta^{-1-}$ mice $(43.98 \pm 2.59)$ versus control animals (36.94 \pm 2.04$)$. These data show that the absence of LXR expression alters peripheral myelin structure in vivo.

\section{LXR ligands inhibit canonical Wnt signaling}

Our next goal was to further study the molecular mechanisms underlying the inhibition of myelin genes by LXR. We have shown recently that the $\mathrm{Wnt} / \beta$-catenin signaling pathway is a major driver of myelin gene expression (Tawk et al., 2011). Here, we examined whether oxysterols can decrease myelin gene expression by inhibiting Wnt signaling. By real-time PCR, we showed that transcripts of the major components of the canonical Wnt pathway are inhibited by LXR ligands in MSC80 cells. 25-OH and TO901317 inhibited DVL2 by 75 and 35\%, respectively (Fig. 7A). DVL3 was inhibited by $75 \%$ (25-OH) and by $80 \%$ (TO901317) (Fig. $7 B)$. The transcription factors TCF1, TCF3, and LEF1 were downregulated by $40 \%$ (TCF1) and 50\% (TCF3 and LEF1) (Fig. $7 C-E)$.

$\beta$-Catenin, the central protein of the canonical Wnt pathway, was also affected by LXR ligands. As a matter of fact, treatment of MSC 80 cells for $24 \mathrm{~h}$ with $25-\mathrm{OH}$ or TO901317 $(10 \mu \mathrm{M})$ was inhibited by $50 \% \beta$-catenin transcript (Fig. $8 A$ ). $\beta$-Catenin protein expression was also decreased by $88 \%$ by $25-\mathrm{OH}$ and $78 \%$ by TO901317 in MSC80 cells (Fig. 8 B). This observation was confirmed in the sciatic nerves of adult $L X R \alpha / \beta^{-/-}$mice, in which $\beta$-catenin protein expression was increased by 3.24 -fold and mRNA expression by $50 \%$ (Fig. $8 C$ ). Because $\beta$-catenin expression was severely affected by the treatment of MSC80 cells with 25OH and TO901317, we wondered whether MPZ and PMP22
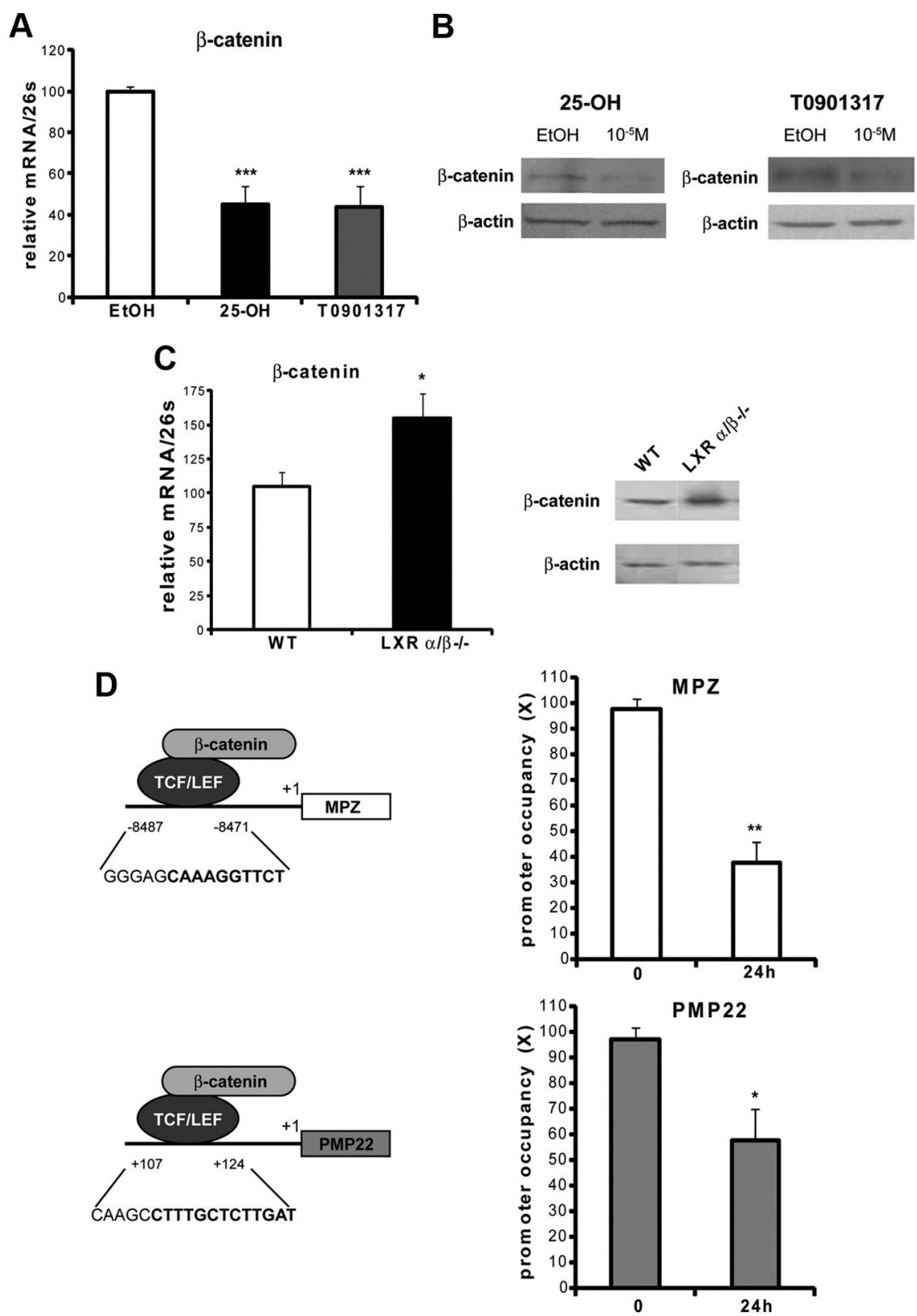

Figure 8. Effect of oxysterols on the recruitment of $\beta$-catenin at the levels of MPZ and PMP22 promoters. A, MSC80 cells were treated with ethanol (vehicle), $25-0 \mathrm{H}$, or T0901317 at $10 \mu \mathrm{m}$ during $24 \mathrm{~h}$. Total RNA was extracted, and quantitative real-time PCR experiments were performed using primers recognizing $\beta$-catenin. The qRT-PCR was normalized using $26 \mathrm{~S}$ RNA, and they represent the means \pm SEM of at least four independent experiments. ${ }^{* * *} p<0.001$ by Tukey's post hoc test after one-way ANOVA when compared with control. $\boldsymbol{B}$, MSC80 cells were treated with ethanol (vehicle), $25-0 \mathrm{H}$, or T0901317 at $10 \mu \mathrm{m}$ during $24 \mathrm{~h}$. Western blots were performed using anti- $\beta$ catenin antibodies to verify its expression in MSC 80 cells. $\beta$-Actin was used to normalize the Western blots. C, Sciatic nerves were isolated from either 8-week-old male wild-type mice (WT) or $L X R \alpha / \beta^{-1-}$ animals. Western blots were performed using anti- $\beta$-catenin antibodies to verify its expression in sciatic nerves. $\beta$-Actin was used to normalize the Western blots. These results were reproduced in three independent experiments, and figures represent a typical experiment. Sciaticnerves were isolated from either 8-week-old maleWT miceor $L X R \alpha / \beta^{-\prime-}$ animals. Total RNA was extracted, and quantitative real-time PCR experiments were performed using primers recognizing $\beta$-catenin. The real-time RT-PCR was normalized using 265 RNA, and they represent the mean \pm SEM of at least four independent experiments. D, TCF/LEF binding sites located in MPZ or PMP22 promoters have been identified previously (Tawk et al., 2011). To examine their occupancy, MSC80 cells were treated or not with $25-\mathrm{OH}(10 \mu \mathrm{m})$ during $24 \mathrm{~h}$ and were then subjected to $\mathrm{ChIP}$ analysis using anti- $\beta$ catenin antibody or 23 antibody as a non-relevant antibody. Quantitative real-time PCR was performed to detect MPZ and PMP22 promoter regions, including TCF/LEF binding elements. Results are the mean of at least four independent experiments. ${ }^{*} p<0.05$ and ${ }^{* *} p<0.01$ by Tukey's post hoc test after one-way ANOVA when compared with control.

promoter occupancy by $\beta$-catenin might be hindered. ChIP analysis showed that $\beta$-catenin recruitment, at the level of the TCF/LEF present on MPZ and PMP22 promoters, was reduced by $6 \%$ and $40 \%$, respectively, after $24 \mathrm{~h}$ of incubation with $25-\mathrm{OH}$ 
(Fig. $8 D$ ). No significant reduction of $\beta$-catenin promoter occupancy was detected between 1 and $8 \mathrm{~h}$ of treatment (data not shown). These results show that $25-\mathrm{OH}$ exerts an inhibitory effect on Wnt signaling and impedes $\beta$-catenin binding on myelin gene promoters.

\section{Discussion}

Here, we demonstrate that the oxysterols $24(S)-\mathrm{OH}, 25-\mathrm{OH}$, and 27-OH, their biosynthetic enzymes (CYP46A1, CH25OH, and CYP27A1), as well as their cognate receptors $(\operatorname{LXR} \alpha$ and $\operatorname{LXR} \beta)$ are present in myelinating Schwann cells and in peripheral nerves, in which they may regulate vital functions by autocrine/ paracrine mechanisms. Our results indeed show that $25-\mathrm{OH}$ and the selective LXR agonist TO901317 are able to downregulate the expression of peripheral myelin genes in Schwann cells: they inhibit MPZ and PMP22 promoter activities, transcripts, and proteins. Their inhibitory effects are mediated by liganded LXR, as demonstrated by ChIP experiments, revealing an increased recruitment of LXR at the levels of MPZ and PMP22 promoters. $\operatorname{LXR} \beta$, but not $\operatorname{LXR} \alpha$, is implicated in the inhibition of MPZ promoter activity by oxysterols, whereas both $\operatorname{LXR} \alpha$ and LXR $\beta$ mediate PMP22 promoter inhibition.

We also show that LXR $\alpha$ and LXR $\beta$ are crucial for the correct myelination of peripheral nerve axons. The knock-out of both LXR $\alpha$ and LXR $\beta$ led to a significant increase in the expression of MPZ and PMP22 transcripts, but to the opposite, to a decrease in myelin proteins and to thinner myelin sheaths. Thus, electron microscopy of sciatic nerves of $L X R \alpha / \beta^{-/-}$mice revealed an alteration of the phenotype of myelin sheaths surrounding axons, without affecting the diameters or the number of axons. This observation could be explained by a dysregulation of myelin protein gene expression in the absence of LXRs, because PMP22 and MPZ are dosage-sensitive genes and their coordinated expression is necessary for efficient myelination. Increase in PMP22 and MPZ transcripts in $L X R \alpha / \beta^{-/-}$mice may thus result in a less efficient myelination of axons. This observation is not surprising because several studies described a congenital hypomyelination of peripheral nerves attributable to MPZ overexpression and its consequent mistargeting to mesaxon membranes (Wrabetz et al., 2000; Yin et al., 2000). LXRs are known to play a key role in the homeostasis of cholesterol, a major lipid constituent of the myelin sheaths and required for myelin membrane (Saher et al., 2005). Elevated cholesterol levels are essential for efficient exiting of MPZ from the endoplasmic reticulum of Schwann cells into the growing myelin sheath (Saher et al., 2009). We have shown that cholesterol transporter ABCA1 is activated by $25-\mathrm{OH}$ and TO901317 in Schwann cells and sciatic nerve. As ABCA1 enhances cholesterol efflux from Schwann cells, the intracellular cholesterol levels are decreased and, as a consequence, MPZ trafficking slowed. We assume that repression of the basal activity of myelin genes by LXR ligands probably avoids an accumulation of MPZ in the ER. Accordingly, LXR pathway must be considered as a central actor in myelination (1) by regulating the cholesterol levels in nerve and (2) by repressing the basal activity of myelin genes.

So far, the regulation of cholesterol metabolism by oxysterols has only been investigated within the context of neurodegenerative diseases, in particular of Alzheimer's disease (Lütjohann et al., 2000; Papassotiropoulos et al., 2002) and multiple sclerosis (Leoni et al., 2002; Teunissen et al., 2003). Also, it has been shown recently that LXR activation by a synthetic ligand results in increased levels of neurosteroids and protection of the sciatic nerve from neuropathy induced by diabetes (Cermenati et al., 2010).
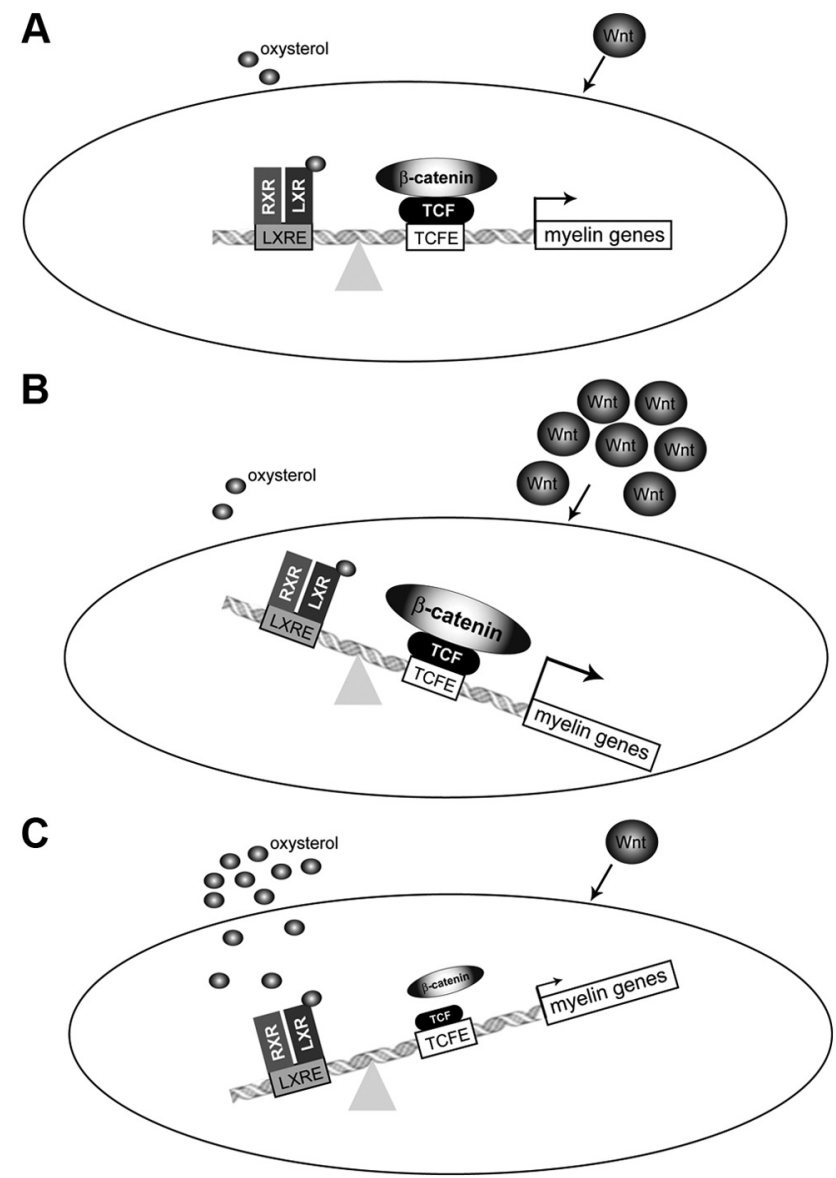

Figure 9. Schematic model of crosstalk between oxysterol and Wnt pathways on the expression of myelin genes MPZ and PMP22. A, At basal levels, the interplay between LXR and Wnt pathways induces the fine-tuning of myelin gene expression. Wnt ligands activate myelin genes by means of the canonical Wnt pathway. We have identified active TCF/LEF response elements (TCFE) on the level of MPZ and PMP22 promoters. These TCFEs bind TCF/LEF transcription factors that interact with $\beta$-catenin. Oxysterols are present in Schwann cells. They repress myelin gene expression by means of LXRs that bind to LXREs located near the TCFEs. Furthermore, oxysterols can decrease the amount of Wnt components in Schwann cells. Therefore, the amount of $\beta$-catenin recruited on the level of MPZ and PMP22 promoters is the result of a balance between Wnt and oxysterol pathways. $\boldsymbol{B}$, When Wnt ligands are at high amounts, $W n t / \beta$-catenin pathway becomes predominant provoking the increase of $\beta$-catenin recruitment on myelin gene promoters. This will allow the expression myelin genes at high levels. $\boldsymbol{C}$, When oxysterols reach high concentrations, they repress myelin gene expression by means of LXRs and decrease the amounts of Wnt/ $\beta$-catenin components in Schwann cells. In this case, the oxysterol/LXR pathway becomes predominant.

Our observations demonstrate for the first time a key role of LXR and its natural oxysterol or synthetic ligands in the myelination process. Accordingly, LXR pathways must be considered as central actors in myelination by regulating cholesterol turnover in peripheral nerves and by fine-tuning myelin gene transcription.

The study of signaling mechanisms involved in the repression of myelin genes has so far been neglected. Our result indicates that locally synthesized oxysterols can dampen the basal activity of myelin genes in vitro and in vivo. This is supported by several lines of evidence: (1) in LXR $\alpha / \beta$ knock-out animals, the expression levels of myelin genes are altered when compared with wildtype animals; and (2) the knock-down of LXRs by siRNA in Schwann cells enhanced the basal expression of myelin genes. Therefore, we assume that oxysterols present in Schwann cells and nerve fibers may contribute to the delicate regulation of myelin gene expression. 
The inhibition of peripheral myelin genes by oxysterols does not implicate the classical mechanism of action of oxysterols. Usually, liganded LXR activate transcription of metabolic genes (e.g., ABC cassettes) after coactivator binding. Only in a few cases have liganded LXRs been shown to repress genes involved in inflammation [e.g., C reactive protein (Blaschke et al., 2006) or coding for metalloprotease 9 (Castrillo et al., 2003)] via a direct interaction with corepressors or other nuclear transcription factors (Castrillo et al., 2003).

A possible mechanism by which LXR ligands repress myelin genes involves the inhibition of the canonical Wnt signaling pathway. We indeed recently demonstrated that the $\mathrm{Wnt} / \beta$-catenin pathway is crucial for the expression of peripheral myelin genes (Tawk et al., 2011). We here show that the transcripts of the major components of the canonical Wnt pathway are inhibited by oxysterols (i.e., DVL, TCF/LEF). Moreover, $\beta$-catenin transcript and protein were also decreased by oxysterols in MSC 80 cells, consistent with their enhanced expression in the sciatic nerves of $L X R \alpha / \beta^{-/-}$animals. ChIP analysis showed that $\beta$-catenin recruitment at the level of the MPZ and PMP22 promoters was reduced after a $24 \mathrm{~h}$ treatment with $25-\mathrm{OH}$ or TO901317. The reduction of $\beta$-catenin could be explained by its potential recruitment by LXR: a direct interaction between LXRs and $\beta$-catenin, through Armadillo repeats, has been described (Uno et al., 2009). This is not surprising, because $\beta$-catenin could be a coregulator for several nuclear receptors (Fonte et al., 2005). TCF/LEF binding sites are close to LXR response elements in MPZ and PMP22 promoters.

Our observation that myelin genes are repressed by oxysterols has several effects. From a physiological and fundamental point of view, our results highlight the complexity of regulation of myelin genes. Two pathways account for the repression by LXR: binding of LXR to myelin gene promoters and inhibition of Wnt signaling pathway (Fig. 9). Schwann cells are able to produce Wnt ligands (Tawk et al., 2011) and oxysterols. Wnt ligands, by means of TCF/LEF and $\beta$-catenin, activate myelin genes, whereas oxysterols, via LXR, repress them (Fig. 9). Interestingly, in both MPZ and PMP22 promoters, TCF/LEF binding sites are close to LXR response elements. This localization could also account for the crosstalk between these pathways. The result of this complex interplay is the fine-tuning of myelin genes expression. It is noteworthy that a slight modification of peripheral myelin gene dosage provokes Charcot-Marie-Tooth type 1 pathology. Therefore, myelin gene regulation must be strictly controlled to avoid any over expression, leading to an alteration of myelin structure or demyelination. Our observations thus open new perspectives for the development of therapies targeting LXR and Wnt signaling mechanisms for the treatment of peripheral neuropathies.

\section{References}

Andersson S, Gustafsson N, Warner M, Gustafsson JA (2005) Inactivation of liver $\mathrm{X}$ receptor beta leads to adult-onset motor neuron degeneration in male mice. Proc Natl Acad Sci U S A 102:3857-3862.

Blaschke F, Takata Y, Caglayan E, Collins A, Tontonoz P, Hsueh WA, Tangirala RK (2006) A nuclear receptor corepressor-dependent pathway mediates suppression of cytokine-induced C-reactive protein gene expression by liver X receptor. Circ Res 99:e88-e99.

Bochelen D, Mersel M, Behr P, Lutz P, Kupferberg A (1995) Effect of oxysterol treatment on cholesterol biosynthesis and reactive astrocyte proliferation in injured rat brain cortex. J Neurochem 65:2194-2200.

Castrillo A, Joseph SB, Marathe C, Mangelsdorf DJ, Tontonoz P (2003) Liver $\mathrm{X}$ receptor-dependent repression of matrix metalloproteinase- 9 expression in macrophages. J Biol Chem 278:10443-10449.

Cermenati G, Giatti S, Cavaletti G, Bianchi R, Maschi O, Pesaresi M, Abbiati
F, Volonterio A, Saez E, Caruso D, Melcangi RC, Mitro N (2010) Activation of the liver $\mathrm{X}$ receptor increases neuroactive steroid levels and protects from diabetes-induced peripheral neuropathy. J Neurosci 30:11896-11901.

Chen JD, Evans RM (1995) A transcriptional co-repressor that interacts with nuclear hormone receptors. Nature 377:454-457.

Cummins CL, Mangelsdorf DJ (2006) Liver X receptors and cholesterol homoeostasis: spotlight on the adrenal gland. Biochem Soc Trans 34:1110-1113.

Désarnaud F, Bidichandani S, Patel PI, Baulieu EE, Schumacher M (2000) Glucocorticosteroids stimulate the activity of the promoters of peripheral myelin protein-22 and protein zero genes in Schwann cells. Brain Res 865:12-16.

Fonte C, Grenier J, Trousson A, Chauchereau A, Lahuna O, Baulieu EE, Schumacher M, Massaad C (2005) Involvement of $\beta$-catenin and unusual behavior of CBP and p300 in glucocorticosteroid signaling in Schwann cells. Proc Natl Acad Sci U S A 102:14260-14265.

Garbay B, Heape AM, Sargueil F, Cassagne C (2000) Myelin synthesis in the peripheral nervous system. Prog Neurobiol 61:267-304.

Hörlein AJ, Näär AM, Heinzel T, Torchia J, Gloss B, Kurokawa R, Ryan A, Kamei Y, Söderström M, Glass CK, Rosenfeld MG (1995) Ligandindependent repression by the thyroid hormone receptor mediated by a nuclear receptor co-repressor. Nature 377:397-404.

Huuskonen J, Fielding PE, Fielding CJ (2004) Role of p160 coactivator complex in the activation of liver X receptor. Arterioscler Thromb Vasc Biol 24:703-708.

Janowski BA, Willy PJ, Devi TR, Falck JR, Mangelsdorf DJ (1996) An oxysterol signalling pathway mediated by the nuclear receptor LXR alpha. Nature 383:728-731.

Leoni V, Masterman T, Diczfalusy U, De Luca G, Hillert J, Björkhem I (2002) Changes in human plasma levels of the brain specific oxysterol 24Shydroxycholesterol during progression of multiple sclerosis. Neurosci Lett 331:163-166.

Liere P, Akwa Y, Weill-Engerer S, Eychenne B, Pianos A, Robel P, Sjövall J, Schumacher M, Baulieu EE (2000) Validation of an analytical procedure to measure trace amounts of neurosteroids in brain tissue by gas chromatography-mass spectrometry. J Chromatogr B Biomed Sci Appl 739:301-312.

Liere P, Pianos A, Eychenne B, Cambourg A, Liu S, Griffiths W, Schumacher M, Sjövall J, Baulieu EE (2004) Novel lipoidal derivatives of pregnenolone and dehydroepiandrosterone and absence of their sulfated counterparts in rodent brain. J Lipid Res 45:2287-2302.

Lütjohann D, Papassotiropoulos A, Björkhem I, Locatelli S, Bagli M, Oehring RD, Schlegel U, Jessen F, Rao ML, von Bergmann K, Heun R (2000) Plasma 24S-hydroxycholesterol (cerebrosterol) is increased in Alzheimer and vascular demented patients. J Lipid Res 41:195-198.

Massaad C, Garlatti M, Wilson EM, Cadepond F, Barouki R (2000) A natural sequence consisting of overlapping glucocorticoid-responsive elements mediates glucocorticoid, but not androgen, regulation of gene expression. Biochem J 350:123-129.

Niemann A, Berger P, Suter U (2006) Pathomechanisms of mutant proteins in Charcot-Marie-Tooth disease. Neuromolecular Med 8:217-242.

Papassotiropoulos A, Lütjohann D, Bagli M, Locatelli S, Jessen F, Buschfort R, Ptok U, Björkhem I, von Bergmann K, Heun R (2002) 24Shydroxycholesterol in cerebrospinal fluid is elevated in early stages of dementia. J Psychiatr Res 36:27-32.

Reynolds ES (1963) The use of lead citrate at a high $\mathrm{pH}$ as electron opaque stain in the electron microscope. J Cell Biol 17:208-212.

Roa BB, Warner LE, Garcia CA, Russo D, Lovelace R, Chance PF, Lupski JR (1996) Myelin protein zero (MPZ) gene mutations in nonduplication type 1 Charcot-Marie-Tooth disease. Hum Mutat 7:36-45.

Russell DW (2000) Oxysterol biosynthetic enzymes. Biochim Biophys Acta 1529:126-135.

Saher G, Brügger B, Lappe-Siefke C, Möbius W, Tozawa R, Wehr MC, Wieland F, Ishibashi S, Nave KA (2005) High cholesterol level is essential for myelin membrane growth. Nat Neurosci 8:468-475.

Saher G, Quintes S, Möbius W, Wehr MC, Krämer-Albers EM, Brügger B, Nave KA (2009) Cholesterol regulates the endoplasmic reticulum exit of the major membrane protein P0 required for peripheral myelin compaction. J Neurosci 29:6094-6104.

Schultz JR, Tu H, Luk A, Repa JJ, Medina JC, Li L, Schwendner S, Wang S, 
Thoolen M, Mangelsdorf DJ, Lustig KD, Shan B (2000) Role of LXRs in control of lipogenesis. Genes Dev 14:2831-2838.

Tawk M, Makoukji J, Belle M, Fonte C, Trousson A, Hawkins T, Li H, Ghandour M, Schumacher M, Massaad C (2011) Wnt/ $\beta$-catenin signaling is an essential and direct driver of myelin gene expression and myelinogenesis. J Neurosci 31:3729-3742.

Teunissen CE, Dijkstra CD, Polman CH, Hoogervorst EL, von Bergmann K, Lütjohann D (2003) Decreased levels of the brain specific 24Shydroxycholesterol and cholesterol precursors in serum of multiple sclerosis patients. Neurosci Lett 347:159-162.

Trousson A, Bernard S, Petit PX, Liere P, Pianos A, El Hadri K, Lobaccaro JM, Said Ghandour MS, Raymondjean M, Schumacher M, Massaad C (2009) 25-hydroxycholesterol provokes oligodendrocyte cell line apoptosis and stimulates the secreted phospholipase A2 type IIA via LXR beta and PXR. J Neurochem 109:945-958.
Uno S, Endo K, Jeong Y, Kawana K, Miyachi H, Hashimoto Y, Makishima M (2009) Suppression of beta-catenin signaling by liver $\mathrm{X}$ receptor ligands. Biochem Pharmacol 77:186-195.

Wang H, Zhang Y, Yehuda-Shnaidman E, Medvedev AV, Kumar N, Daniel KW, Robidoux J, Czech MP, Mangelsdorf DJ, Collins S (2008) Liver $\mathrm{X}$ receptor alpha is a transcriptional repressor of the uncoupling protein 1 gene and the brown fat phenotype. Mol Cell Biol 28: 2187-2200.

Wrabetz L, Feltri ML, Quattrini A, Imperiale D, Previtali S, D’Antonio M, Martini R, Yin X, Trapp BD, Zhou L, Chiu SY, Messing A (2000) P(0) glycoprotein overexpression causes congenital hypomyelination of peripheral nerves. J Cell Biol 148:1021-1034.

Yin X, Kidd GJ, Wrabetz L, Feltri ML, Messing A, Trapp BD (2000) Schwann cell myelination requires timely and precise targeting of $\mathrm{P}(0)$ protein. J Cell Biol 148:1009-1020. 